\title{
Vibrissae-Evoked Behavior and Conditioning before Functional Ontogeny of the Somatosensory Vibrissae Cortex
}

\author{
Margo S. Landers and Regina M. Sullivan \\ Department of Zoology, University of Oklahoma, Norman, Oklahoma 73019
}

The following experiments determined that the somatosensory whisker system is functional and capable of experiencedependent behavioral plasticity in the neonate before functional maturation of the somatosensory whisker cortex. First, unilateral whisker stimulation caused increased behavioral activity in both postnatal day (P) 3-4 and P8 pups, whereas stimulationevoked cortical activity $\left({ }^{14} \mathrm{C} 2\right.$-deoxyglucose autoradiography) was detectable only in $\mathrm{P} 8$ pups. Second, neonatal rat pups are capable of forming associations between whisker stimulation and a reinforcer. A classical conditioning paradigm (P3-P4) showed that the learning groups (paired whisker stimulationshock or paired whisker stimulation-warm air stream) exhibited significantly higher behavioral responsiveness to whisker stim-

The rat mystacial vibrissae somatosensory system processes environmental tactile cues from the facial whiskers. Mystacial vibrissae are active tactile organs used to scan object surfaces (Welker, 1964; Woolsey and Van der Loos, 1970; Carvell et al., 1991) and extract detailed and complex information (Simons, 1995, 1997; Carvell and Simons, 1996; Nicolelis et al., 1996). Both behavioral plasticity (Steiner and Huston, 1992; Steiner and Gerfin, 1994; Bermejo et al., 1996; Siucinska and Kossut, 1996) and experience-induced cortical plasticity (Delacour et al., 1987; Kossut, 1992; Welker et al., 1992; Diamond et al., 1993; ArmstrongJames et al., 1994; Armstrong-James, 1995; Nicolelis et al., 1995; Joublin et al., 1996; Siucinska and Kossut, 1996; Warren and Dykes, 1996; Simons, 1997; Kossut and Siucinska, 1998) have been demonstrated as a result of adult whisker manipulations.

However, far more dramatic plasticity can be seen in the adult somatosensory system as a result of neonatal manipulations (Van der Loos and Woolsey, 1973; Simons and Land, 1987; Carvell and Simons, 1996; Maier et al., 1996). For example, neonatal (younger than P4) whisker removal or whisker deafferentation results in the loss of corresponding barrel representations (Van der Loos and Woolsey, 1973; Killackey et al., 1978; Nicolelis et al., 1996) with a corresponding disruption of adult whisker dependent behaviors, including a loss in the ability to orient the snout properly (Symons and Tees, 1990) and discriminate surface textures (Carvell and Simons, 1996).

Received Jan. 4, 1999; revised March 25, 1999; accepted March 30, 1999.

This work was funded by National Institute of Mental Health Grant HD33402 and National Science Foundation Grant IBN-9814837 (to R.M.S.). This work was done in partial completion of the requirements for the Master of Science degree (to M.S.L.). We thank Drs. Don Wilson, Thomas Woolsey, and Mark Jacquin for advice on initial aspects of this work. We also thank Victoria Perez and Brian Yeaman for their assistance in data collection.

Correspondence should be addressed to Dr. Regina M. Sullivan, Department of Zoology, University of Oklahoma, Norman, OK 73019.

Copyright (C) 1999 Society for Neuroscience $0270-6474 / 99 / 195131-07 \$ 05.00 / 0$ ulation than controls. Finally, stimulus-evoked somatosensory cortical activity during testing [P8; using ${ }^{14} \mathrm{C}$ 2-deoxyglucose (2-DG) autoradiography] was assessed after somatosensory conditioning from P1-P8. No learning-associated differences in stimulus-evoked cortical activity were detected between learning and nonlearning control groups. Together, these experiments demonstrate that the whisker system is functional in neonates and capable of experience-dependent behavioral plasticity. Furthermore, in contrast to adult somatosensory classical conditioning, these data suggest that the cortex is not required for associative somatosensory learning in neonates.

Key words: vibrissae; whiskers; development; learning; neural plasticity; barrels; somatosensory cortex; behavioral plasticity

Rats are born with whiskers; fine whiskers in follicles appear early [embryonic day (E) 12] (Yamakato and Yohro, 1979), and specialization of follicle sensory mechanoreceptors occurs at E20 (English et al., 1980) well before the maturation of trigeminal ganglia and nuclei (by P1; Taber, 1963; Forbes and Welt, 1981). After thalamic barreloid maturation at P2, the cortical barrel field first appears at P3-P5 (Rice et al., 1985). The system is vulnerable to manipulations during early somatotopic pattern development (Weller and Johnson, 1975; Harris and Woolsey, 1979; Henderson et al., 1992, 1994; Fox, 1995; Rhoades et al., 1996). Thalamocortical afferents modify barrel pattern before P5 (Schlaggar and O'Leary, 1994; Rice, 1995). However, it is unclear whether the whisker system is behaviorally functional in the neonate before whisking movements develop at approximately P12 (Welker, 1964).

Tactile stimulation in the perioral area is critical for neonate survival. Depriving the neonate of perioral sensation, including the whiskers and oral region, disrupts essential behaviors such as nipple attachment, and survival rate is greatly reduced (Hofer et al., 1976; Hofer, 1981; Larson and Stein, 1984; Distel and Hudson, 1985; Morrow-Tesch and McGlone, 1990). However, the specific role of whiskers in these behavioral effects and whether the whisker system is behaviorally functional in the neonate are still unclear.

The present experiments were designed to determine whether neonatal rats are functionally responsive to stimulation of the whiskers and to assess potential behavioral and cortical neural plasticity in the whisker system. Results show that the neonatal whisker system is functional and capable of associative behavioral plasticity (Landers and Sullivan, 1999), although this plasticity may be mediated by subcortical structures.

\section{MATERIALS AND METHODS}

Subjects. The subjects were male and female rat pups born of LongEvans rats (Harlan Sprague Dawley, Indianapolis, IN) in the vivarium at 
the University of Oklahoma. No more than one male and one female from a litter were used in an experimental condition. Dams were housed in rectangular polypropylene cages $(34 \times 29 \times 17 \mathrm{~cm})$ lined with wood chips in a temperature-controlled $\left(20^{\circ} \mathrm{C}\right)$ and light-controlled room $(12 \mathrm{hr}$ light/dark cycle). Ad libitum food and water were available at all times. Births were checked twice daily. The day of birth was considered to be P0. Pups were tested at either P3-P4 (as barrels begin to appear; Rice et al., 1985) or at P8 (as stimulus-evoked cortical 2-DG uptake approaches adult levels; Kossut and Hand, 1984; Wu and Gonzalez, 1997).

Behavioral assessments. To evaluate whether neonatal rat pups can respond to whisker stimulation, we assessed pup behavior during unilateral whisker stimulation at P3-P4 and P8. Pups were removed from the mother and placed in plastic Petri dishes $(100 \mathrm{~mm}$ diameter, $15 \mathrm{~mm}$ height) and left unrestrained. A 10 min acclimation period preceded the experimental session to allow for recuperation from experimental handling. Unilateral whisker stimulation consisted of manually stimulating the whiskers for $30 \mathrm{sec}(\sim 50$ sweeps back and forth across the entire whisker field), using a wooden rod $1 \mathrm{~mm}$ in diameter. Stimulation included repeated flexion of every mystacial vibrissae, without stimulating the intravibrissal hair or skin on the snout. The side of the snout that was stimulated was alternated between litters to control for potential laterality bias of individual pups (Tobet et al., 1993). Behavior was recorded $10 \mathrm{sec}$ before stimulation and during whisker stimulation (30 sec), using a motor activity scale based on the number of elements moved, and was sustained for $2 \mathrm{sec}$ (Hall, 1979; Sullivan et al., 1991). The activity scale range was from $0-5$ [ 0 , no movement; 1 , movement of one element (i.e., head or a limb); 2 , movements of two elements (i.e., treading); 3 , movements of three elements (i.e., pivot); 4, movements of four elements (i.e., locomotion); 5, movements of five elements (i.e., roll over)]. This rating scale frequently has been used to assess neonatal rat behavior and measures changes in general motor activity, which is the characteristic response of the motorically immature neonatal rat pup to presentation of a stimulus (Hall, 1979). Pups were returned immediately to the mother after completion of the session.

Associative conditioning. To assess potential behavioral plasticity in the whisker system, we used both an appetitive and an aversive classical conditioning paradigm. The conditioned stimulus (CS) was always $30 \mathrm{sec}$ of unilateral whisker stimulation (described above) and the unconditioned stimulus (US) was a gentle stream of warm air (US, $10 \mathrm{sec}$ stream of warm air) for appetitive conditioning and a moderate shock (US, 0.5 sec, $0.5 \mathrm{~mA}$ shock to the hind trunk) for aversive conditioning. Paired experimental subjects were given eight pairings of the CS and US with a 3 min intertrial interval (ITI). Conditioning control groups included CS-only (eight $30 \mathrm{sec}$ unilateral whiskers stimulation trials, 3 min ITI), US-only (eight US's, 3 min ITI), and/or random CS-US (eight presentations each of the CS and US, with the CS presented at an ITI of $3 \mathrm{~min}$ and the US presented randomly between the CS presentations with the constraint of nonoverlapping CS-US presentations). Equal numbers of males and females were assigned to each of the conditioning groups. The side of the snout receiving vibrissae stimulation was alternated between each litter.

For pups used in the behavioral plasticity experiments, the pups received only one training session at $\mathrm{P} 3-\mathrm{P} 4$. For the neural assessment experiment the pups received daily training from P1 through P8 to maximize learning (totaling eight sessions). Training was videotaped occasionally to verify that pups in different conditions were treated similarly.

A behavioral rating scale (described above; Hall, 1979) was used to monitor the acquisition of conditioned responses (CR) to whisker stimulation during training. Behavior was observed for $10 \mathrm{sec}$ before each whisker stimulation for a "pre" score and during each whisker stimulation before US onset for the "during" score.

Behavior test. In addition to acquisition curves, pup learning also was assessed by assessing pups' responsiveness to five CS-only presentations. At $4 \mathrm{hr}$ after training the pups again were removed from the mother and placed in the clean Petri dishes, given 10 min to acclimate, and then given five $30 \mathrm{sec}$ unilateral whisker stimulations ( $3 \mathrm{~min}$ ITI). All aspects of testing were consistent with those used during training and are described above. An observer blind to the experimental conditions of pups was used for testing when available.

${ }^{14} \mathrm{C}$ 2-deoxyglucose autoradiography. To determine whether the somatosensory cortex responds to stimulation of the whiskers and to assess potential cortical neural plasticity in the whisker system, we assessed neural activity of the cortex via ${ }^{14} \mathrm{C} 2$-deoxyglucose autoradiography (2-DG; $20 \mu \mathrm{Ci} / 100 \mathrm{gm}$; Sullivan et al., 1991). Pups were handled simi- larly to those used for behavioral testing, except that the 2-DG was injected $5 \mathrm{~min}$ before the start of whisker CS-only presentations and a greater number of whisker CS-only presentations were used to accommodate the longer period of testing required for 2-DG (45 $\mathrm{min})$. Then the pups were decapitated and their brains quickly removed. For tangential sectioning of the barrel field, brains first were bisected midsagittally, and the cortical hemispheres were removed. The cortex was mounted on a pedestal with Tissue Tek, flattened with a glass coverslip, and frozen with dry ice, followed by immersion of the brain in 2-methylbutane at -30 to $-40^{\circ} \mathrm{C}$ and stored in a $-70^{\circ} \mathrm{C}$ freezer. For sectioning, frozen brains were equilibrated to $-20^{\circ} \mathrm{C}$ in a cryostat; sections were cut at 40 $\mu \mathrm{m}$, mounted on subbed glass coverslips, and dried on a slide warmer for 5-10 min. Some sections were mounted on subbed slides and put aside for succinic dehydrogenase staining (SDH; Killackey and Belford, 1979; Jablonska et al., 1995) to verify the location of the cortical barrel field.

Then coverslips containing the 2-DG brain sections were exposed to Kodak BioMax MB x-ray film for $4 \mathrm{~d}$ in an exposure cassette. A set of ${ }^{14} \mathrm{C}$-labeled methylmethacrylate standards previously calibrated to the same concentration of ${ }^{14} \mathrm{C}$ uptake in brain sections was exposed with each sheet of film. Autoradiographs were developed with standard film development techniques and GBX solutions.

The autoradiographs were analyzed by an MCID computer-based digital image processor from Imaging Research (St. Catherine's, Ontario, Canada); the person analyzing the films was unaware of the experimental condition of the autoradiograph. Measurements were taken from the cortex contralateral to stimulation. For each brain section of each pup the optical density was averaged over five samples in the whisker somatosensory cortex and over an additional five samples in an adjacent region of the somatotopic map corresponding to the visual cortex (Chapin and Lin, 1990; Rice, 1995). For each brain section the means of each of the two brain areas were calculated, and the ratio of 2-DG uptake in the somatosensory cortex and visual cortex was calculated. For each pup there was an average of seven brain sections (range, 5-9). Via this method an optical density ratio represented the density found in stimulated areas relative to nonstimulated areas of the same brain section.

\section{RESULTS}

\section{Neonatal rat pups respond to whisker stimulation}

Both P3-P4 $(n=12)$ and P8 $(n=12)$ pups responded to whisker stimulation [main effect of treatment, ANOVA; $F_{(1,20)}=49.7$; $p<0.0001$; no significant effect of age and of treatment $\times$ age interaction]. A Fisher post hoc test revealed that both P3-P4 and P8 pups exhibited an increase in activity during the whisker stimulation relative to prestimulation $(p<0.05)$. Pup responsiveness to stimulation was characterized by an increase in behavioral activity, accompanied by occasional head-up and head turns toward and away from the stimulation. Occasional mouthing movements were observed also.

\section{Only P8 pups exhibited 2-DG uptake in the whisker somatosensory cortex}

Autoradiography indicated that P8, but not P3-P4, pups express a significant increase in 2-DG activity in the primary somatosensory cortex contralateral to whisker stimulation (Fig. 1; main effect of treatment $\times$ age, ANOVA; $\left.F_{(1,9)}=16.6 ; p<0.01\right)$. Figure 2 depicts a 2-DG autoradiograph for the stimulated and nonstimulated P4 and P8 barrel cortex and a neighboring section stained with SDH (P4). These data, using assessments within the barrel field, support previous studies by Wu and Gonzalez (1997), which suggest that layer 4 (coronal sections) of the somatosensory cortex does not express stimulation-evoked 2-DG activity until P7, after the barrel field pattern is defined and layer 4 upper tier thalamocortical afferents are mature (Melzer et al., 1994; Wu and Gonzalez, 1997). Therefore, it appears as if neonatal rat pups are capable of behaviorally responding to whisker stimulation without the involvement of the somatosensory cortex. 


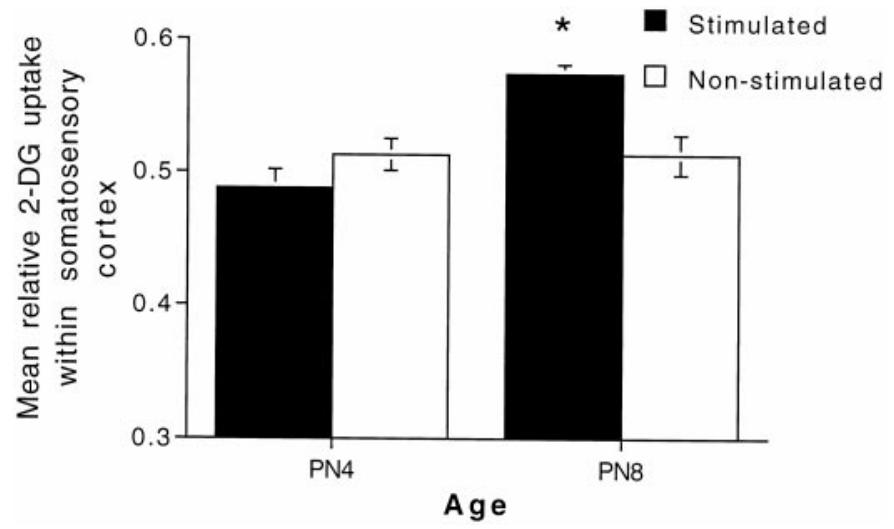

Figure 1. Whisker stimulation produced a stimulus-evoked increase in relative focal 2-DG uptake in the contralateral whisker cortical barrel field of $\mathrm{P} 8$ rat pups, but not in $\mathrm{P} 3-\mathrm{P} 4$ rat pups. The asterisk represents a significant difference $(p<0.05)$ between stimulated and nonstimulated pups.

\section{Neonatal rat pups (P3) can learn an association by using whiskers}

Association of a whisker stimulation CS with an appetitive warm airstream US produced rapid acquisition of a conditioned behavioral activation. As shown in Figure $3 A 2$, during training the pups in the paired training group $(n=10)$ acquired a CR of increased activity to the whisker CS (during the $20 \mathrm{sec}$ before onset of the reward) as compared with pups receiving whisker stimulation CS-alone $(n=10$; repeated measures ANOVA, group $\times$ trial interaction; $\left.F_{(3,54)}=21.79 ; p<0.01\right)$. Fisher post hoc tests revealed that paired pups showed significantly more stimulusevoked activation than control pups beginning at trials 3-4 ( $p<$ 0.01). This CR was specific to the CS because pre-CS behavior (i.e., just before pups received each whisker stimulation) did not differ between groups (Fig. $3 A 1 ; F_{(1,18)}=3.857, \mathrm{NS}$ ).

The CR to the whisker stimulation CS was maintained for at least 4 hr. As shown in Figure 3B, pups trained with the whisker CS paired with a warm air US showed an enhanced behavioral $\mathrm{CR}$ to CS-only trials $4 \mathrm{hr}$ after testing as compared with pups originally trained in the control group $\left[t_{(18)}=4.46 ; p<0.001\right]$. During testing the CR had similar characteristics to the unconditioned response (UR) to the warm air stream; that is, presentation of the US produced behavioral activation similar to the UR, and the CS elicited increased behavioral activation after conditioning similar to the $\mathrm{CR}$.

Similar results were obtained by using a moderate shock $(0.5$ $\mathrm{mA}$ ) as the US (Fig. 4). As shown in Figure 4A2, the whiskershock paired group $(n=8)$ expressed a significant increase in behavioral activity in response to whisker stimulation CS (during the $29 \mathrm{sec}$ before onset of the reward) as compared with random $(n=8)$ and CS-only $(n=8)$ groups during training (repeated measures ANOVA; group $\times$ trial interaction; $F_{(3,63)}=19.38 ; p<$ 0.01). Because US-only pups $(n=8)$ did not receive the CS during training, their response to this stimulation could not be observed. Post hoc Fisher tests revealed that paired pups showed significantly more activation than control pups by trials 3-4 $(p<$ $0.05)$. As shown in Figure $4 A 1$, the pups in groups receiving shock also showed a mild, nonspecific increase in behavioral activity over the course of training that was statistically significant, although this cannot account for the CS-specific response

\section{PN4}

\section{Non -stimulated}

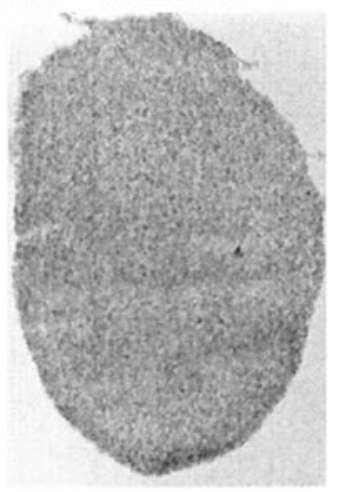

Stimul ated

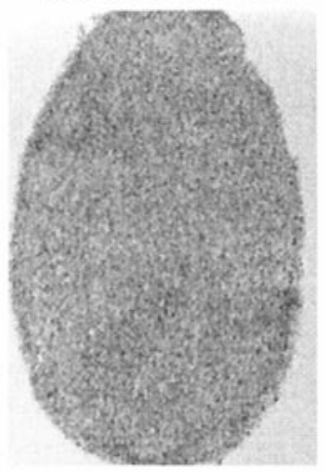

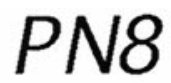

Non - stimulated

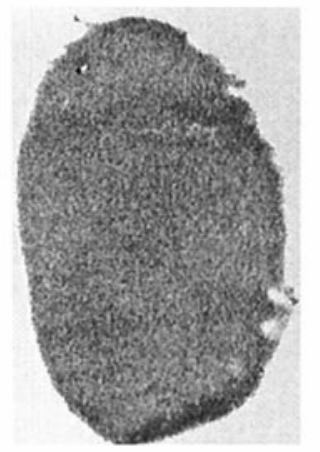

Stimulated

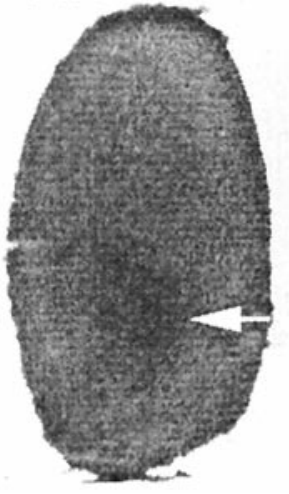

Figure 2. Representative autoradiographs of tangential sections through the cortical barrel field in P4 (left) and P8 (right) rat pups. The figure in the center is a neighboring section from the $\mathrm{P} 4$ rat stained for succinic dehydrogenase. This $\mathrm{SDH}$-stained section includes four rows of the barrel field representing the facial vibrissae, which are marked by arrows. Stimulation of the contralateral whiskers evoked an increase in 2-DG uptake in the cortical barrel field of $\mathrm{P} 8$ pups relative to nonstimulated P8 pups (arrow). In P4 pups, however, no whisker stimulationevoked increase in cortical barrel field 2-DG uptake was detected. 


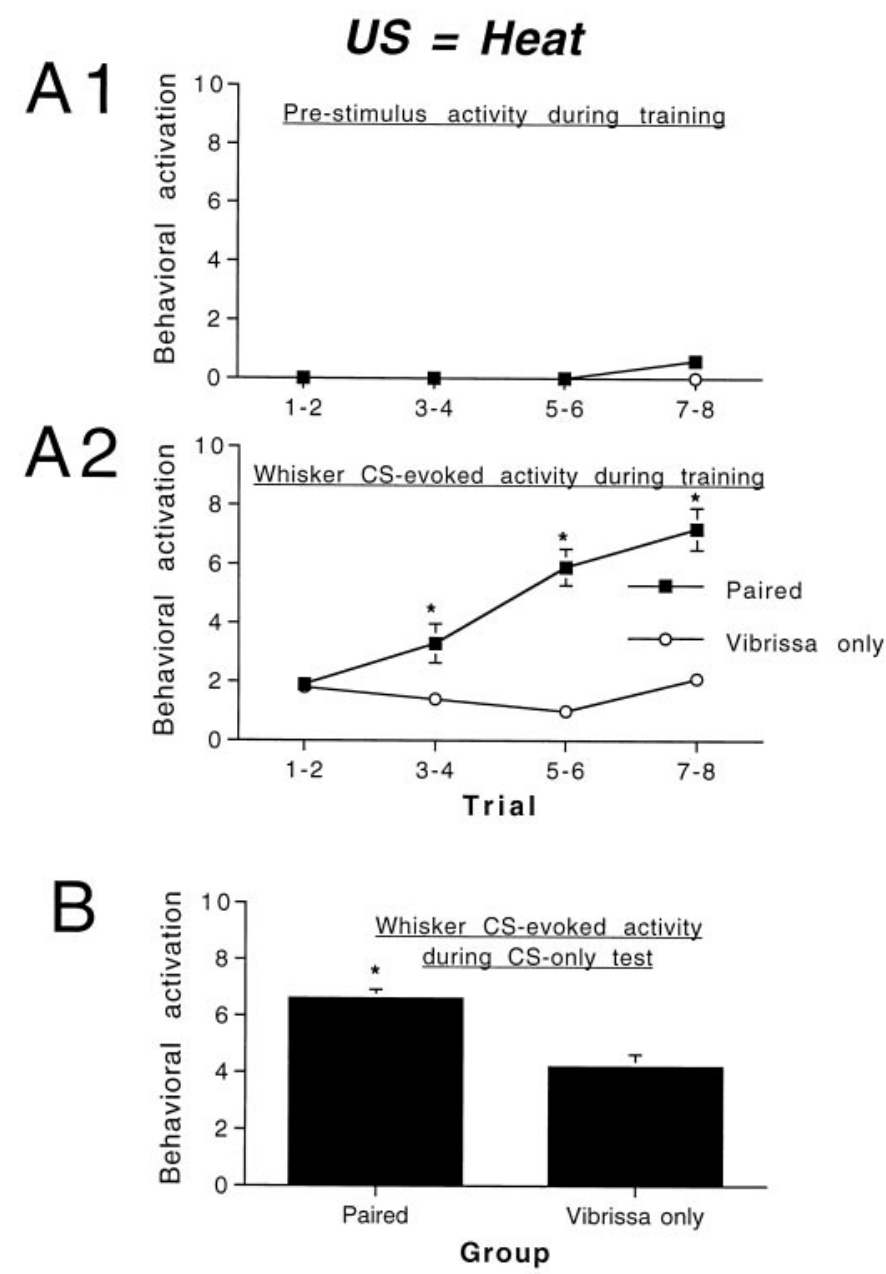

Figure 3. Associative pairing of a whisker (conditioned stimulus, CS) and heat from a warm air stream (unconditioned stimulus, US) produced a conditioned behavioral activation response (generalized increase in behavioral activity) to the whisker CS alone. Behavioral activity before the onset of each CS remained relatively stable over the course of conditioning $(A 1)$, whereas CS-evoked activity increased over repeated trials $(A 2)$ in pups in the paired group as compared with the control pups. $B$, Subsequent CS-only tests ( $4 \mathrm{hr}$ after conditioning) revealed a significant CS-evoked behavioral response in paired pups relative to controls. Asterisks represent a significant difference between paired and control groups; $p<0.05$.

(pre-CS activity; repeated measures ANOVA; group $\times$ trial interaction; $\left.F_{(3,63)}=4.81 ; p<0.01\right)$.

As shown in Figure $4 B$, pups trained with the whisker CS paired with a shock US showed an enhanced behavioral CR to CS-only trials $4 \mathrm{hr}$ after testing as compared with control pups (ANOVA; main effect of group; $F_{(3,28)}=36.22 ; p<0.001$ ). Post hoc Fisher tests revealed that pups receiving paired whisker stimulation and shock US had higher CS-evoked activity levels at testing relative to control groups $(p<0.01)$ and that the random, CS-only, and US-only groups were not significantly different from one another. During testing the CR had similar characteristics to the UR elicited by shock; that is, presentation of the US produced behavioral activation, and the CS elicited increased behavioral activation after conditioning. However, the shock US also elicited vocalization and behavior that could be interpreted as escape behavior, and these behaviors were not elicited by the CS after learning. This is consistent with aversive conditioning in the

\section{US = Shock}

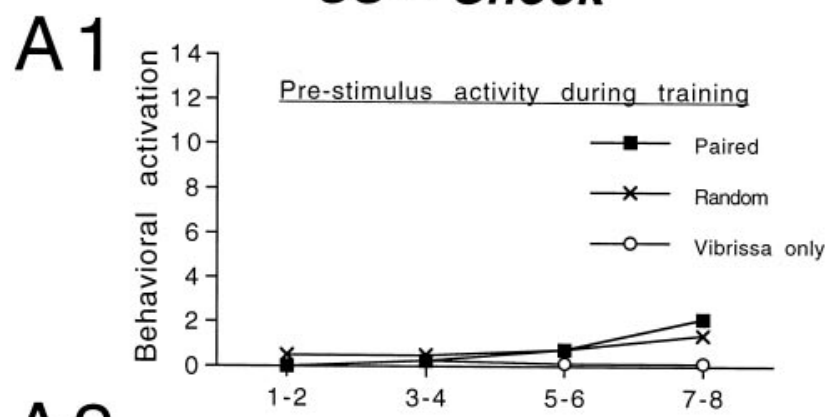

A2

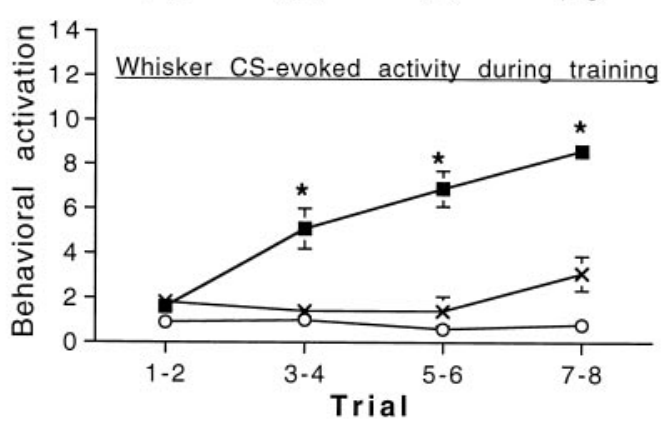

$\mathrm{B}$

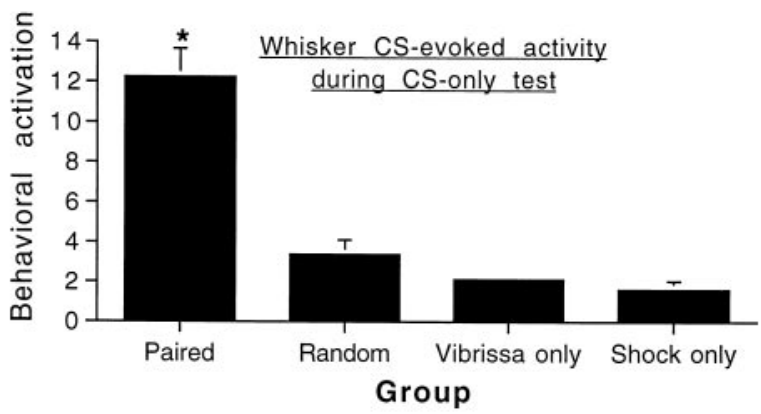

Figure 4. Associative pairing of a whisker CS and an electric shock US produced a conditioned behavioral activation response (generalized increase in behavioral activity) to the whisker CS alone. Behavioral activity before the onset of the CS remained relatively stable over the course of conditioning (A1), although pups in shocked groups showed a slight increase in activity. CS-evoked activity increased over repeated trials (A2) in pups in the paired group as compared with pups in all control groups. $B$, Subsequent CS-only tests (4 hr after conditioning) revealed a significant CS-evoked behavioral response in paired pups relative to controls. Asterisks represent a significant difference between paired and control groups; $p<0.05$.

olfactory system of neonatal rats (Camp and Rudy, 1988; Miller et al., 1990; Wilson and Sullivan, 1994).

\section{Neonatal somatosensory learning in the whisker system does not appear to involve cortical barrel changes}

Although stimulus-evoked increases in relative 2-DG uptake were detected in the P8 whisker somatosensory cortex, no differences were found in stimulus-evoked relative 2-DG uptake between different training conditions after $8 \mathrm{~d}$ of conditioning (Fig. $5 ; F_{(3,19)}=2.33$, NS).

\section{DISCUSSION}

These experiments provide the first demonstration of behavioral responsiveness to whisker stimulation before the onset of whisking (P12; Welker, 1964) and indicate that this system is behaviorally functional in the first week of life during the period of 


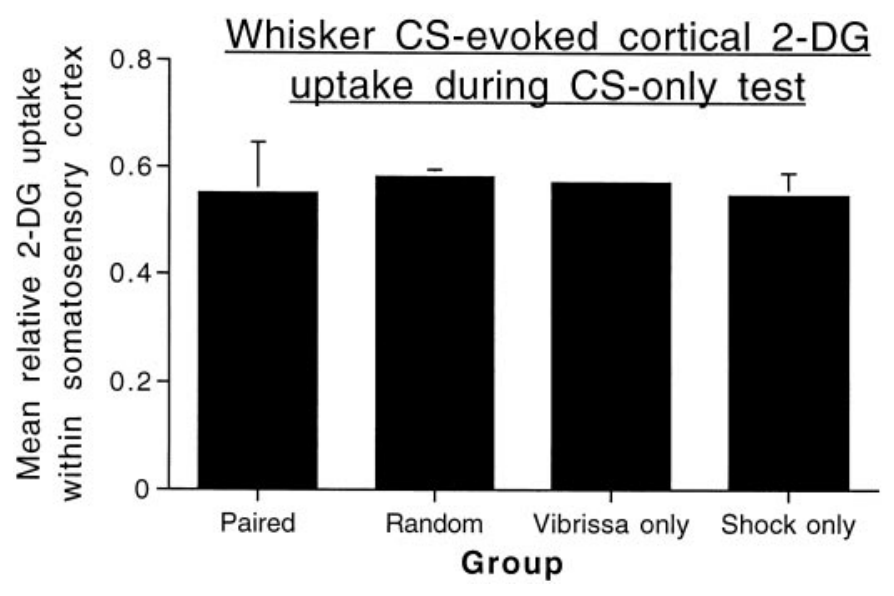

Figure 5. Mean relative whisker CS-evoked 2-DG uptake in the cortical barrel field in P8 pups after $8 \mathrm{~d}$ of conditioning. No learning-associated significant differences were detected among groups.

initial cortical development. Stimulation of mystacial whiskers caused increased behavioral activity as early as P3, before the onset of stimulus-evoked barrel cortical activity as measured by 2-DG autoradiography. Furthermore, these experiments demonstrate that the neonatal rat pup whisker system is capable of the experience-dependent behavioral plasticity demonstrated by classical conditioning. The inability to detect stimulus-evoked somatosensory cortical 2-DG uptake in $\mathrm{P} 3-\mathrm{P} 4$ pups and a failure to detect learning-correlated differences in 2-DG uptake in the cortical whisker somatosensory system of P8 pups suggest that neonatal associative learning in this system may rely on earlierdeveloping subcortical structures. Experience-dependent structural or functional modification of subcortical circuits, however, may lead to subsequent changes in the development of the cortex that were not examined here specifically (Woolsey, 1990; Florence and Kaas, 1995; Ralston et al., 1996; Sengelaub et al., 1997; Kilgard and Merzenich, 1998). These data are in sharp contrast to both 2-DG and other neurophysiological studies with whisker somatosensory classical conditioning in adults in which cortical changes are associated with classical conditioning (Siucinska and Kossut, 1996; Butt et al., 1997; Kossut and Siucinska, 1998) and other temporally correlated presentations of stimuli (Clark et al., 1988; Wang et al., 1995; Weinberger, 1995; Zhou and Fuster, 1997; Maalouf et al., 1998).

The present data indicate that the whiskers of the rat pup are functional and responsive to stimulation in P3-P4 pups, before the onset of sensory-evoked activation of the somatosensory cortex (Kossut and Hand, 1984; Wu and Gonzalez, 1997; present study). The sensory-evoked behavior examined here was a nonspecific behavioral activation, similar to that observed in rat pups caused by olfactory stimulation (Sullivan et al., 1991; Sullivan and Wilson, 1993). In neonates, behavioral activation evoked by odors has been hypothesized to be mediated by subcortical structures, whereas more specific responses-e.g., odor approach/avoidance responses-may be mediated by "higher," potentially cortical structures (Kucharski and Hall, 1988; Sullivan and Wilson, 1993; Rudy, 1994). For example, bilateral amygdala lesions in P5 rat pups disrupt the acquisition of conditioned odor approach responses but do not affect conditioned behavioral activation to odors (Sullivan and Wilson, 1993). Thus, it is suggested that the neonatal whisker system, although behaviorally functional, probably lacks the ability to perform detailed sensory discriminations and the stimulus analyses shown by the mature somatosensory system. However, given the present demonstration of behavioral responsiveness to whisker stimulation early in the ontogeny of cortical function, behaviorally relevant early sensory input could play a major role in cortical development via experience-induced changes in trigeminal and thalamic nuclei.

The hypothesized role of subcortical mediation of whiskerevoked behavior and conditioning is similar to that observed in the neonatal olfactory system. Neonatal olfactory conditioning involves structural and functional modification early in the olfactory pathway (olfactory bulb; Wilson et al., 1987; Sullivan et al., 1989; Woo and Leon, 1991). Several subcortical loci in the vibrissae somatosensory pathway could be involved in neonatal behavioral responses to whisker stimuli. Trigeminal and thalamic somatosensory nuclei appear functional early in development, and normal sensory-evoked activity in those structures is required for proper functional organization of higher centers in the pathway (for review, see Armstrong-James, 1995; Diamond, 1995; Henderson and Jacquin, 1995; Keller, 1995). Here again, neonatal somatosensory behavior and conditioning may be similar to those reported for the olfactory system. Additionally, subcortical learning has been documented in a variety of adult sensory systems, clearly indicating that the cortex is not necessary for at least some forms of simple learning (Tsukahara et al., 1981; Wall et al., 1985; Iwata et al., 1986; Lennartz and Weinberger, 1992; Albrecht and Davidowa, 1993; Edeline, 1998).

An additional similarity between neonatal somatosensory and olfactory conditioning is their dependence on norepinephrine (NE). Both the behavioral and neural plasticities induced by neonatal olfactory conditioning involve and require $\mathrm{NE}$ from the locus coeruleus (for review, see Wilson and Sullivan, 1994). Similarly, the behavioral whisker conditioning in neonates described here involves and requires NE (Landers and Sullivan, 1999). It is hypothesized that the association of whisker stimulation and NE release induced by the unconditioned stimulus induces synaptic modifications that result in enhanced behavioral responsiveness to subsequent whisker stimulation alone. As in neonatal olfactory conditioning, this association may occur early in the somatosensory pathway. The locus coeruleus innervates the somatosensory system at a number of different levels along the ascending somatosensory pathway (Simpson et al., 1997), and NE has been implicated in development, function, and plasticity within this system (Osterheld-Haas et al., 1994; Warren and Dykes, 1996; Levin et al., 1998; Waterhouse et al., 1998). Studies currently are underway to identify the subcortical nuclei critical for whiskerevoked behaviors in neonates. The critical role of NE in neonatal learning is in sharp contrast to that of the adult in which NE has long been known to have a modulatory effect on learning, memory, and its expression (Mason, 1984; Harley, 1987; Fillenz, 1990; Liang et al., 1990; Sara et al., 1994).

Recent studies from our laboratory suggest that the stimulation of whiskers in neonatal rat pups is behaviorally relevant even before the onset of whisking. For example, neonatal rat pups use their whiskers in nipple attachment and during social interactions with siblings. Specifically, dewhiskered pups (P3-P4) with an otherwise normal perioral area take a longer time to attach to their mother's nipples and appear less active when interacting with a sibling (Young and Sullivan, 1997). Conditioned behavioral activation has been demonstrated to enhance ongoing behaviors such as huddling and milk ingestion in neonates (Sullivan et al., 1986). Under natural conditions the association of maternal stimulation (such as tactile stimulation, warmth, and milk) with 
whisker stimulation could result in a learned change in behavioral state that would facilitate infant responsiveness to the dam and siblings, as has been demonstrated for learned odor cues (Sullivan et al., 1986). The relatively nonspecific sensory information required to produce this critical behavioral response could be controlled entirely by subcortical pathways and, thus, may not dependent on the late-developing neocortex. Experience-induced plasticity in these subcortical circuits also could have important consequences for subsequent cortical development.

\section{REFERENCES}

Albrecht D, Davidowa H (1993) Extraretinal modulation of geniculate neuronal activity by conditioning. Prog Brain Res 95:271-286.

Armstrong-James M (1995) The nature and plasticity of sensory processing within adult rat barrel cortex. In: Cerebral cortex, Vol 11, The barrel cortex of rodents (Jones EG, Diamond I, eds), pp 333-368. New York: Plenum.

Armstrong-James M, Diamond ME, Ebner FF (1994) An innocuous bias in whisker use in adult rats modifies receptive fields of barrel cortex neurons. J Neurosci 14:6978-6991.

Bermejo R, Harvey M, Gao P, Zeigler HP (1996) Conditioned whisking in the rat. Somatosens Mot Res 13:225-233.

Butt AE, Myasnikov AA, Dykes RW (1997) Auditory-somatosensory conditioning produces long-lasting changes in the response properties of single neurons in the vibrissae region of the rat somatosensory cortex. Soc Neurosci Abstr 23:175.20.

Camp LL, Rudy JW (1988) Changes in the categorization of appetitive and aversive events during postnatal development of the rat. Dev Psychobiol 21:25-41.

Carvell GE, Simons DJ (1996) Abnormal tactile experience early in life disrupts active touch. J Neurosci 16:2750-2757.

Carvell GE, Simons DJ, Lichtenstein N, Seth H, Bryant P (1991) Electromyographic activity of mystacial pad musculature during whisking behavior in the rat. Somatosens Mot Res 8:159-164.

Chapin JK, Lin CS (1990) The somatic sensory cortex of the rat. In: The cerebral cortex of the rat (Kolb B, Tees RC, eds), pp 341-358. Boston: MIT.

Clark SA, Allard T, Jenkins WM, Merzenich MM (1988) Receptive fields in the body-surface map in adult cortex defined by temporally correlated inputs. Nature 332:444-445.

Delacour J, Houcine O, Talbi B (1987) "Learned" changes in the responses of the rat barrel field neurons. Neuroscience 23:63-71.

Diamond ME (1995) Somatosensory thalamus of the rat. In: Cerebral cortex, Vol 11, The barrel cortex of rodents (Jones EG, Diamond I, eds), pp 189-220. New York: Plenum.

Diamond ME, Armstrong-James M, Ebner FF (1993) Experiencedependent plasticity in adult rat barrel cortex. Neurobiology 90:2082-2086.

Distel H, Hudson H (1985) The contribution of the olfactory and tactile modalities to the nipple-search behavior of newborn rabbits. J Comp Physiol [A] 157:599-605.

Edeline J (1998) Learning-induced physiological plasticity in the thalamo-cortical sensory systems: a critical evaluation of receptive field plasticity, map changes, and their potential mechanisms. Prog Neurobiol 57:165-224.

English KB, Burgess PR, Kavka-van Norman D (1980) Development of rat Merkel cells. J Comp Neurol 194:475-496.

Fillenz M (1990) Noradrenergic neurons. Cambridge: Cambridge UP.

Florence SL, Kaas JH (1995) Large-scale reorganization at multiple levels of the somatosensory pathway follows therapeutic amputation of the hand in monkeys. J Neurosci 15:8083-8095.

Forbes DJ, Welt C (1981) Neurogenesis in the trigeminal ganglion of the albino rat: a quantitative autoradiographic study. J Comp Neurol 199:133-137.

Fox K (1995) The critical period for long-term potentiation in primary sensory cortex. Neuron 15:485-488.

Hall WG (1979) Feeding and behavioral activation in infant rats. Science 205:206-209.

Harley C (1987) A role for norepinephrine in arousal, emotion, and learning? Limbic modulation by norepinephrine and the Kety hypothesis. Prog Neuropsychopharmacol Biol Psychiatry 11:419-458.

Harris RM, Woolsey TA (1979) Morphology of Golgi-impregnated neu- rons in mouse cortical barrels following vibrissae damage at different postnatal ages. Brain Res 161:143-149.

Henderson TA, Jacquin MF (1995) What makes subcortical barrels? Requisite trigeminal circuitry and developmental mechanisms. In: Cerebral cortex, Vol 11, The barrel cortex of rodents (Jones EG, Diamond I, eds), pp 123-188. New York: Plenum.

Henderson TA, Woolsey TA, Jacquin MF (1992) Infraorbital nerve blockade from birth does not disrupt central trigeminal pattern formation in the rat. Dev Brain Res 66:146-152.

Henderson TA, Johnson EM, Osborn PA, Jacquin MF (1994) Fetal NGF augmentation preserves excess trigeminal ganglion cells and interrupts whisker-related pattern form. J Neurosci 14:3384-3403.

Hofer MA (1981) Effects of infraorbital nerve section on survival, growth, and suckling behaviors of developing rats. J Comp Physiol Psychol 95:123-133.

Hofer MA, Shair H, Singh P (1976) Evidence that maternal ventral skin substances promote suckling in infant rats. Physiol Behav 17:131-136.

Iwata J, LeDoux JE, Reis DJ (1986) Destruction of intrinsic neurons in the lateral hypothalamus disrupts cardiovascular but not behavioral conditioned emotional responses. Brain Res 368:161-166.

Jablonska B, Gierdalski M, Siucinska E, Skangiel-Kramska J, Kossut M (1995) Partial blocking of NMDA receptors restricts plastic changes in adult mouse barrel cortex. Behav Brain Res 66:207-216.

Joublin F, Spengler F, Wacquant S, Dinse HR (1996) A columnar model of somatosensory reorganizational plasticity based on Hebbian and non-Hebbian learning rules. Biol Cybern 74:275-286.

Keller A (1995) Synaptic organization of the barrel cortex. In: Cerebral cortex, Vol 11, The barrel cortex of rodents (Jones EG, Diamond I, eds), pp 221-262. New York: Plenum.

Kilgard MP, Merzenich MM (1998) Cortical map reorganization enabled by nucleus basalis activity. Science 279:1714-1718.

Killackey HP, Belford GR (1979) The formation of afferent patterns in the somatosensory cortex of the neonatal rat. J Comp Neurol 183:285-304.

Killackey HP, Ivy GO, Cunningham TJ (1978) Anomalous organization of thalamocortical projections consequent to vibrissae removal in the newborn rat and mouse. Brain Res 155:136-140.

Kossut M (1992) Effects of single sensory deprivation upon a single cortical column: a 2-DG study. Exp Brain Res 90:639-642.

Kossut M, Hand P (1984) The development of the vibrissal cortical column: a 2-deoxyglucose study. Neurosci Lett 48:1-6.

Kossut M, Siucinska E (1998) Learning-induced expansion of cortical maps-what happens to adjacent cortical representations? NeuroReport 9:4025-4028.

Kucharski D, Hall WG (1988) Developmental changes in the access to olfactory memories. Behav Neurosci 102:340-348.

Landers MS, Sullivan RM (1999) Norepinephrine and associative conditioning in the neonatal rat somatosensory system. Dev Brain Res, in press.

Larson MA, Stein BE (1984) The use of tactile and olfactory cues in neonatal orientation and localization of the nipple. Dev Psychobiol 17:423-436.

Lennartz RC, Weinberger NM (1992) Frequency-specific receptive field plasticity in the medial geniculate body induced by Pavlovian fear conditioning is expressed in the anesthetized brain. Behav Neurosci 106:484-497.

Levin BE, Craik RL, Hand PJ (1988) The role of norepinephrine in adult rat somatosensory cortical metabolism and plasticity. Brain Res 443:261-271.

Liang KC, McGaugh JL, Yao HY (1990) Involvement of amygdala pathways in the influence of post-training intra-amygdala norepinephrine and peripheral epinephrine on memory storage. Brain Res 508:225-233.

Maalouf M, Dykes RW, Miasnikov AA (1998) Effects of D-AP5 and NMDA microiontophoresis on associative learning in the barrel cortex of awake rats. Brain Res 793:149-168.

Maier DL, Marron M, He Y, Joe-Yen S, McCasland JM (1996) Widespread activation of barrel cortex by small numbers of neonatally spared whiskers. Somatosens Mot Res 13:245-253.

Mason ST (1984) Catecholamines and behavior. Cambridge: Cambridge UP.

Melzer P, Welker E, Dorfl J, Van der Loos H (1994) Maturation of the neuronal metabolic response to vibrissae stimulation in the developing whisker-to-barrel pathway of the mouse. Dev Brain Res 77:227-250.

Miller JS, Molina JC, Spear NE (1990) Ontogenetic differences in the 
expression of odor-aversion learning in 4- and 8-day-old rats. Dev Psychobiol 19:37-47.

Morrow-Tesch J, McGlone JJ (1990) Sensory systems and nipple attachment behavior in neonatal pigs. Physiol Behav 47:1-4.

Nicolelis MA, Baccala LA, Lin RC, Chapin JK (1995) Sensorimotor encoding by synchronous neural ensemble activity at multiple levels of the somatosensory system. Science 268:1353-1358.

Nicolelis MA, Oliveira L, Lin R, Chapin JK (1996) Active tactile exploration influences the functional maturation of the somatosensory system. J Neurophysiol 75:2192-2196.

Osterheld-Haas MC, Van der Loos H, Hornung JP (1994) Monoaminergic afferents to cortex modulate structural plasticity in the barrel field of the mouse. Dev Brain Res 77:189-202.

Ralston HJ, Ohara PT, Meng XW, Wells J, Rolston DD (1996) Transneuronal changes of the inhibitory circuitry in the macaque somatosensory thalamus following lesions of the dorsal column nuclei. J Comp Neurol 22:325-335.

Rhoades RW, Crissman RS, Bennett-Clarke CA, Killackey HP, Chiaia NI (1996) Development and plasticity of local intracortical projections within the vibrissae representation of the rat primary somatosensory cortex. J Comp Neurol 370:524-535.

Rice FL (1995) Comparative aspects of barrel structure and development. In: Cerebral cortex, Vol 11, The barrel cortex of rodents (Jones EG, Diamond I, eds), pp 1-76. New York: Plenum.

Rice FL, Gomez C, Barstow C, Burnet A, Sands P (1985) A comparative analysis of the development of the primary somatosensory cortex: interspecies similarities during barrel and laminar development. J Comp Neurol 236:477-495.

Rudy JW (1994) Ontogeny of context-specific latent inhibition of conditioned fear: implications for configural associations theory and hippocampal formation development. Dev Psychobiol 27:367-379.

Sara S, Vankov A, Herve A (1994) Locus coeruleus-evoked responses in behaving rats: a clue to the role of noradrenaline in memory. Brain Res Bull 35:457-465.

Schlaggar BL, O'Leary DM (1994) Early development of the somatotopic map and barrel patterning in rat somatosensory cortex. J Comp Neurol 346:80-96.

Sengelaub DR, Muja N, Mills AC, Myers WA, Churchill JD, Garraghty PE (1997) Denervation-induced sprouting of intact peripheral afferents in the cuneate nucleus of adult rats. Brain Res 769:256-262.

Simons DJ (1995) Neuronal integration in the somatosensory whisker/ barrel cortex. In: Cerebral cortex, Vol 11, The barrel cortex of rodents (Jones EG, Diamond I, eds), pp 263-298. New York: Plenum.

Simons DJ (1997) Rodent whisker barrels: window into cerebral cortical function. News Physiol Sci 12:268-273.

Simons DJ, Land PW (1987) Early experience of tactile stimulation influences organization of somatic sensory cortex. Nature 326:694-697.

Simpson KL, Altman DW, Wang L, Kirifides MI, Lin RC, Waterhouse BD (1997) Lateralization and functional organization of the locus coeruleus projection to the trigeminal somatosensory pathway in rat. J Comp Neurol 385:135-147.

Siucinska E, Kossut M (1996) Short-lasting classical conditioning induces reversible changes of representational maps of vibrissae in mouse SI cortex: a 2-DG study. Cereb Cortex 96:506-513.

Steiner H, Gerfen CR (1994) Tactile sensory input regulates basal and apomorphine-induced immediate early gene expression in rat barrel cortex. J Comp Neurol 344:297-304.

Steiner H, Huston JP (1992) Control of turning behavior under apomorphine by sensory input from the face. Psychopharmacology 109:390-394.

Sullivan RM, Wilson DA (1991) Neural correlates of conditioned odor avoidance in infant rat. Behav Neurosci 105:307-312.

Sullivan RM, Wilson DA (1993) Role of the amygdala complex in early olfactory associative learning. Behav Neurosci 107:254-263.

Sullivan RM, Wilson DA (1994) The locus coeruleus, norepinephrine, and memory in newborns. Brain Res Bull 35:467-472.

Sullivan RM, Hofer MA, Brake S, Williams CL (1986) Huddling and independent feeding of neonatal rats is enhanced by a conditioned change in behavioral state. Dev Psychobiol 19:625-635.
Sullivan RM, Wilson DA, Leon M (1989) Norepinephrine and learninginduced plasticity in infant rat olfactory system. J Neurosci 9:3998-4006.

Sullivan RM, McGaugh JL, Leon M (1991) Norepinephrine-induced plasticity and one-trial olfactory learning in neonatal rats. Dev Brain Res 60:219-228.

Symons LA, Tees RC (1990) An examination of the intramodal and intermodal behavioral consequences of long-term vibrissae removal in rats. Dev Psychobiol 23:849-867.

Taber E (1963) Histogenesis of brainstem neurons studied autoradiographically with thymidine- $\mathrm{H}^{3}$ in the mouse. Anat Rec 145:291.

Tobet SA, Roca AL, Crandall JE (1993) Cellular organization in rat somatosensory cortex: effects of sex and laterality. Exp Neurol 121:65-76.

Tsukahara N, Oda Y, Notsu T (1981) Classical conditioning mediated by the red nucleus in the cat. J Neurosci 1:72-79.

Van der Loos H, Woolsey TA (1973) Somatosensory cortex: structural alterations following early injury to sense organs. Science 1796:395-397.

Wall JT, Gibbs CM, Broyles JL, Cohen DH (1985) Modification of neuronal discharge along the ascending tectofugal pathway during visual conditioning. Brain Res 342:67-76.

Wang X, Merzenich MM, Sameshima K, Jenkins WM (1995) Remodeling of hand representation in adult cortex determined by timing of tactile stimulation. Nature 378:13-14.

Warren RA, Dykes RW (1996) Transient and long-lasting effects of iontophoretically administered $\mathrm{NE}$ on somatosensory cortical neurons in halothane anesthetized rats. Can J Physiol Pharmacol 74:38-57.

Waterhouse BD, Moises HC, Woodward DJ (1998) Phasic activation of the locus coeruleus enhances responses of primary sensory cortical neurons to peripheral receptive field stimulation. Brain Res 790:33-44.

Weinberger NM (1995) Dynamic regulation of receptive fields and maps in the adult sensory cortex. Annu Rev Neurosci 18:129-158.

Welker E, Rao SB, Dorfl J, Melzer P, Van der Loos H (1992) Plasticity in the barrel cortex of the adult mouse: effects of chronic stimulation upon deoxyglucose uptake in the behaving animal. J Neurosci 12:153-170.

Welker WI (1964) Analysis of sniffing of the albino rat. Behavior 12:223-244.

Weller LW, Johnson JI (1975) Barrels in cerebral cortex altered by receptor disruption in newborn but not in 5-day-old mice (Cricetidea and Muridae). Brain Res 83:504-508.

Wilson DA, Sullivan RM (1994) Neurobiology of associative learning in the neonate: early olfactory learning. Behav Neural Biol 61:1-18.

Wilson DA, Sullivan RM, Leon M (1987) Single-unit analysis of postnatal olfactory learning: modified olfactory bulb output neuron response patterns to learned attractive odors. J Neurosci 7:3154-3162.

Woo CC, Leon M (1991) Increase in a focal population of juxtaglomerular cells in the olfactory bulb associated with early learning. J Comp Neurol 305:49-56.

Woolsey TA (1990) Peripheral alterations and somatosensory development. In: Development of sensory systems in mammals (Coleman JR, ed), pp 461-516. New York: Wiley.

Woosley TA, Van der Loos H (1970) The structural organization of layer IV in the somatosensory region (SI) of mouse cerebral cortex. Brain Res 17:205-242.

Wu CC, Gonzalez MF (1997) Functional development of the vibrissae somatosensory system of the rat: ${ }^{14} \mathrm{C} 2$-deoxyglucose metabolic mapping study. J Comp Neurol 384:323-336.

Yamakato M, Yohro T (1979) Subdivision of mouse vibrissae on an embryological basis with descriptions of variations in the number and arrangement of sinus hairs and cortical barrels. Am J Anat 155:153-174.

Young T, Sullivan RM (1997) Vibrissae function in neonatal rats. Annu Meeting Anim Behav Soc.

Zhou Y, Fuster JM (1997) Neuronal activity of somatosensory cortex in a cross-modal (visuo-haptic) memory task. Exp Brain Res 116:551-555. 